\title{
Exploring the Emerging Impact of Metro Rail Transit (MRT-3) in Metro Manila
}

\author{
Tomas U. Ganiron Jr \\ Te Roopu Taurima O Manukau, Otahuhu, Auckland \\ DOST Engineering and Science Education Project (ESEP).Taguig City \\ Qassim University, College of Architecture, Almulyda, Buraidah City \\ tomasuganironjr@gmail.com
}

\begin{abstract}
This study focuses on the different elements of Metro Rail Transit (MRT-3) operation with the aim of characterizing MRT operation and putting in context its impact in terms of what it is best designed for and what it can deliver. This also involves analyzing the status of the operations of MRT-3 in terms of accessibility to passengers, routing and convenience and determination of the factors affecting development of the MRT system. The study further concludes that the resources for MRT improvement are scarce, and maintenance and management of the work done are hardly enough. However, MRT-3 is best designed to substitute conventional railway services on routes where much higher capacity is required and to reduce travel time, further improving the railway service, also against other modes, therefore leading to mode substitution.
\end{abstract}

Keywords: Highway engineering, railway transit, road engineering, transportation engineering

\section{Introduction}

The Metro Rail Transit (MRT-3), also known as Metrostar Express, is `public good and has been seen as serving a number of purposes and producing a number of public benefits. These public benefits can be categorized into two; direct and indirect benefits. The direct benefits of rail transit systems are defined in terms of accessibility improvement impacts. This is due to the fact that the original function of MRT investment is simply to improve the accessibility of city centers for those living in residential areas. For example, MRT in various cities such as Pasay, Makati, Mandaluyong and Quezon to have reduced average commute travel times to the city centers. This is evidently true for those residents who live in surrounding areas of MRT stations. For instance, 50,000 commuting hours saved per-work-day has been estimated for Quezon City, and a similar reduction is also found for Makati City and Pasay City. These benefits are due in part to the separation of MRT from motor vehicle congestion. However, MRT have other indirect benefits which address more modern concerns such as congestion relief, reduction in per capita road-traffic accidents, energy savings, environmental advantages, improved personal mobility for disadvantaged groups and transit-oriented development. MRT can also produce negative externalities such as traffic congestion, noise pollution effects, safety and visual clutter effects for residents who reside too close to a railway station and line, hence, may negatively affect property values.

The twentieth century witnessed a dramatic increase in private vehicle ownership such as cars and trucks. Due to this dramatic increase, most in Metro Manila have struggled with traffic and parking congestion problems especially in city centers. Traffic congestion leads to negative effects such as increased travel time for motorists and their passengers, increased levels of pollution (noise and air) and 
increased tardiness, stress, frustration and to potentially cause road-traffic accidents. In addition, increasing time spent in congested traffic results in exposure to air pollution. However, traffic congestion could be reduced through the improvement of public transportation such as by constructing MRT. This is because MRT can provide the quickest means of transport in the most congested travel corridors, convenient and be able to carry up large number of passengers.

For instance, MRT can generally carry up to 36,000 passengers per hour in one direction. MRT have reduced car-driving and benefiting not only transit passengers but also car occupants on the less congested roadways. Reducing vehicles on the roads by only a few percentage points can significantly reduce congestion levels, mainly for daily commuting and freight movement. Arguably, this positive effect can only be achieved if MRT can draw people out of their cars.

As reported by [1], between October 2007 and May 2009, the number of passengers who travelled by rail transit was about 1.2 million, and most of these passengers were former car users. The reduction in traffic congestion can result in reducing the rate of road-traffic accidents as fewer car trips made.

In Metro Manila for instance, road-traffic accidents have cost 1-2 per cent of their gross domestic product (GDP) each year [2]. Moreover, most of the road-traffic accidents victims are often young adults whose families rely on their earnings. The Philippine National Police Commission on Road Traffic Injury Prevention as cited by [3] estimated that more than 3000 people were killed and 977 people were injured in road-traffic accidents in 1998. These figures continue to rise with the increasing number of vehicles on the roads. In Metro Manila for instance, 24 per cent of children deaths are caused by road-traffic accidents. The phenomenon of road-traffic accidents could be reduced by constructing MRT as the systems are much safer than cars. In addition, areas served by good quality of MRT are found to have much lower per capita traffic fatality rates among young adults and the elderly residents. This is the outcome from delaying young adult vehicle ownership and reducing vehicle use by the elderly residents.

Furthermore, the construction of MRT has potentially played a significant role in stimulating transit-oriented development (TODs). In more developed countries such as the UK and US, their rail transit systems have created compact and mixed-use urban villages around stations [4]. As a result, residents around these areas tend to own fewer cars and drive less than if they were to live in more automobile independent neighborhoods.

It is important to note that the above mentioned benefits/values associated with the construction of MRT such as congestion relief, reduced per capita road accidents, energy savings, environmental advantages, improved personal mobility for disadvantaged groups and transit-oriented development are well known. These benefits can conveniently be found through cost-benefit analysis - usually carried out by developers before any project can be implemented.

This research aims to identify the impact including the trends and issues of MRT 3 in Metro Manila Despite its apparent important role in decongesting the city transportation network, it has not seen any improvement in the intensification of the network (thus services) within the city and its environs. This is particularly in reference to the existing rail network and its impact on the delivery of mass transit rail services in Metro Manila and its environs.

\section{Technological Evolution of Metro Rail Transit 3}

The Metro Rail Transit 3 (MRT-3) is the cornerstone of the Department of Transportation \& Communication's (DOTC) integrated strategy to alleviate the chronic traffic congestion experience along the EDSA corridor. The Metro Rail 
system is designed to carry in excess of 23,000 passengers per hour per direction, initially, and is expandable to accommodate 48,000 passengers per hour, per direction.

The DOTC awarded a contract to Metro Rail Transit Corporation (MRTC) to build, lease and transfer the Metro Rail Transit System, under the BOT laws of the Republic of the Philippines. The scheme required the DOTC to hold the franchise and run the system particularly the operation and the collection of fares. The MRTC built the system, maintain the same as to guarantee the availability of the trains at specified headway at specified hours, as well as to procure the required spare parts, the DOTC pays MRTC monthly fees for a certain number of years.

MRTC financed the construction of the EDSA MRT III, a 16.9-kilometer modern rail system to stretch along EDSA's 10.5-meter median from North Avenue in Quezon City to Taft Avenue, Pasay City. They also infused US\$ 190 million (P4.49 billion) in equity into the project.

MRTC obtained financial closing, with the help of international financial consultant JP Morgan, for loans worth US\$ 465 million P 12.32 billion) from the Bank of Tokyo-Mitsubishi, and Japan Export-Import Bank (JEXIM); the Postal Bank of the Czech Republic and Czech Export Credit Agency; and a group of local banks on October 17, 1997. The loans are backed by the government through a sovereign undertaking, as agreed with the Department of Finance, to cushion risks to investors and creditors.

\subsection{History of MRT-3}

During the construction of the first line of the Manila Light Rail Transit System in the early 1980s, Electrowatt Engineering Services of Zürich designed a comprehensive plan for metro service in Metro Manila. The plan-still used as the basis for planning new metro lines-consisted of a 150-kilometer (93 mi) network of rapid transit lines spanning all major corridors within 20 years, [1] including a line on Epifanio de los Santos Avenue, the region's busiest road corridor.

The MRT-3 (originally LRT-3) project officially began in 1989, five years after the opening of the LRT Line 1, with the Hong Kong-based EDSA LRT Corporation winning the public bidding for the line's construction [4]. However, construction never commenced, with the project stalled as the Philippine government conducted several investigations into alleged irregularities with the project's contract [2]. A consortium of local real estate companies, led by Fil-Estate Management, later formed the Metro Rail Transit Corporation (MRTC) in June 1995 and took over the EDSA LRT Corporation [4].

The MRTC was subsequently awarded a Build-Operate-Transfer contract by the DOTC, which meant that the latter would possess ownership of the system and assume all administrative functions, such as the regulation of fares and operations, leaving the MRTC responsibility over construction and maintenance of the system as well as the procurement of spare parts for trains. In exchange, the DOTC would pay the MRTC monthly fees for a certain number of years to reimburse any incurred costs [3].

Construction began on the fifteenth of October 1996, with a BOT agreement signed between the Philippine government and the MRTC [5]. An amended turnkey agreement was later signed on September 16, 1997 with a consortium of companies (including Mitsubishi Heavy Industries and Sumitomo Corporation, and a local company, EEI Corporation, which was subcontracted for civil works). A separate agreement was signed with ČKD on rolling stock. MRTC also retained the services of ICF Kaiser Engineers and Constructors to provide program management and technical oversight of the services for the design, construction management and commissioning $[3,6]$. 
During construction, the MRTC oversaw the design, construction, equipping, testing, and commissioning, while the DOTC oversaw technical supervision of the project activities covered by the BOT contract between the DOTC and MRTC. The DOTC also sought the services of Systra, a French consultant firm, with regards to the technical competence, experience and track record in the construction and operations [3].

On December 15, 1999, the initial section from North Avenue to Buendia was inaugurated by President Joseph Estrada, [4] with all remaining stations opening on July 20, 2000, a little over a month past the original deadline [5]. However, ridership was initially far below expectations, with passengers complaining of the stations' steep stairs and the general lack of connectivity with other modes of public transportation [6].Passengers also complained of high ticket prices, with the maximum fare of $\mathrm{P} 34$ at the time being significantly higher than a comparable journey on those lines operated by the LRTA and PNR. Although the MRTC projected 300,000-400,000 passengers riding the system daily, in the first month of operation the system saw a ridership of only 40,000 passengers daily [9].The system was even criticized as a white elephant alongside the Manila Light Rail Transit System and the Metro Manila Skyway [7, 8].

To alleviate passenger complaints, the MRTC later retrofitted stations with escalators and elevators for easier access, as well as reducing passenger fares. By 2004, the MRT-3 had the highest ridership of the three lines, with 400,000 passengers daily. On August 13, 2014 the train on the Taft Avenue Station got derailed and overshot to the streets, first the train stopped right after Magallanes Station because of a technical problem, then the first train stopped working so they used the second train to push the first train, while pushing the first train got detached from the rest and broke the concrete barriers and fell down to the streets. On the said incident at least 38 people got injured [8].

\subsection{MRT-3 Trains}

As shown in Figure 1, the rail project has a fleet of 73 Czech-made modern and air-conditioned rail cars, of which up to 60 , in three-car trains, will be operating daily during hours. The trains were built by CKD Doprovni System of Prague, the Czech Republic. The rail vehicles are articulated, eight-axle, three-section cars, designed for single-ended operations [3,9].

Each rail car is provided with five double leaf, electronically-operated, plugsliding doors. The three center doors have an open width of 1,255 millimeters (mm.) while the two end doors, $861 \mathrm{~mm}$. Each train can seat 80 passengers and carry, under crush loading conditions, 394 commuters at any one time. The MRT3 trains can carry 23,000 passengers per hour per direction daily.

The rail coaches are also air and noise pollution-free and run on electricity from MERALCO. 34.5 kilovolts AC Power is provided at the eight traction electrification substations at North Avenue, Kamuning, Santolan Road, Ortigas Avenue, Guadalupe, Ayala Avenue, Magallanes Avenue and Taft Avenue.

The trains run at a maximum speed of 65 kilometers per hour, enough to cover the rail system's tip in about 30 minutes, including short dwell times of about 25 to 35 seconds in each of the system's 13 stations. They run over standard rail tracks.

Aside from the two revenue tracks, a pocket track is located at the Shaw Blvd. Station for the temporary storage of disabled cars, for temporary storage of cars cut from the train consist during non-peak hours, or for mid-point train turn-backs where scheduling needs or passengers load dictates. 


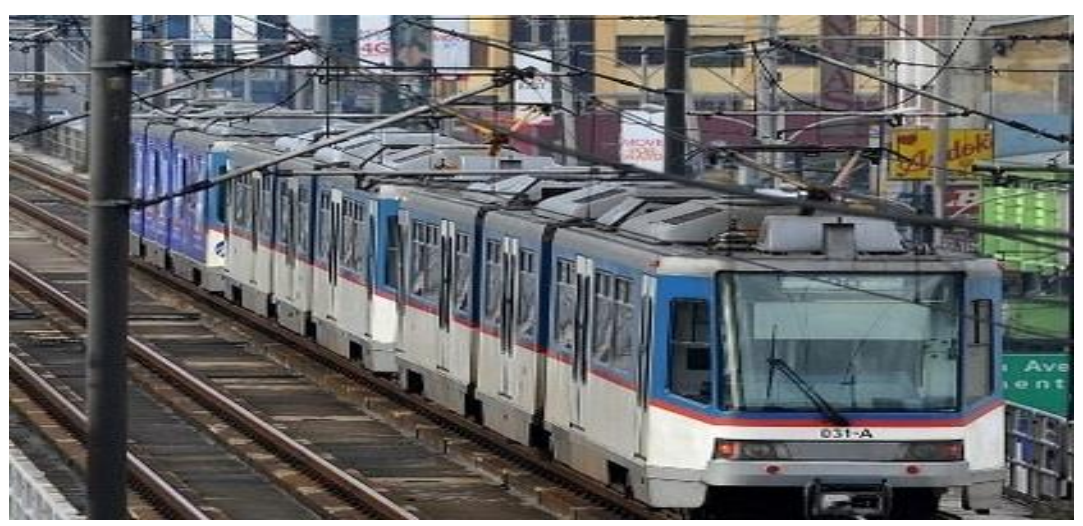

Figure 1. MRT 3 Train

\subsection{Stations Layout and Accessibility}

MRT-3 stations have a standard layout, with a concourse level and a platform level. The concourse is usually above the platform, with stairs, escalators and elevators leading down to the platform level. Station concourses contain ticket booths, which is separated from the platform level by fare gates $[4,10]$.

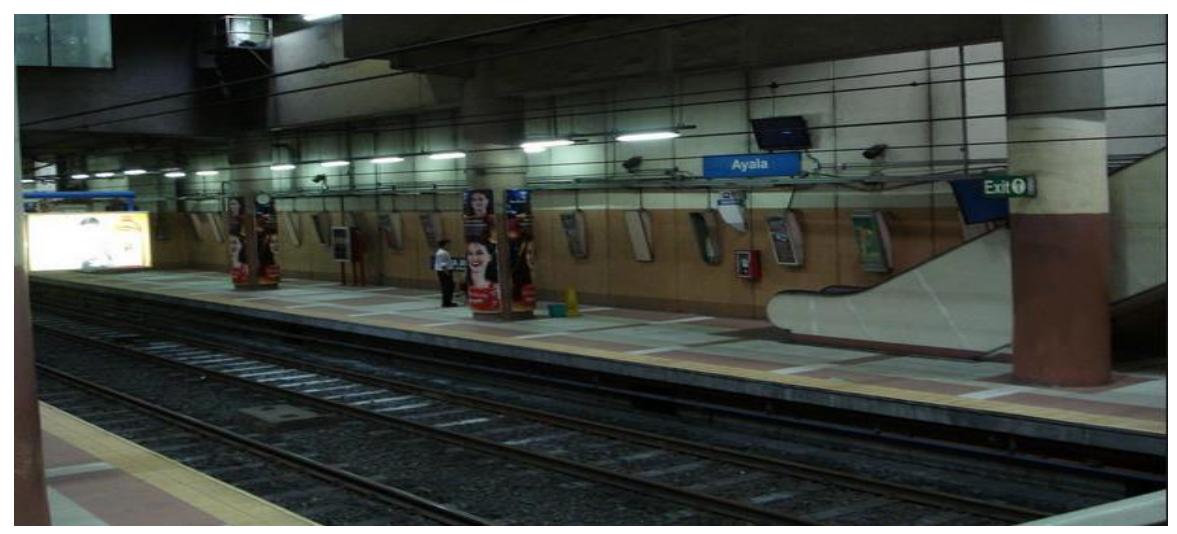

Figure 2. Taft Avenue Island Platform

Some stations, such as Araneta Center-Cubao, are connected at concourse level to nearby buildings, such as shopping malls, for easier accessibility. Most stations are also barrier-free inside and outside the station, and trains have spaces for passengers using wheelchairs [4].

Stations either have island platforms, such as Taft Avenue shown in Figure 2 and Shaw Boulevard, or side platforms, such as Ortigas and North Avenue.

Part of the platform corresponding to the front car of the train is cordoned off for the use of women, children, elderly and disabled passengers.

MRT-3 stations are also designed to occupy the entire span of EDSA, allowing passengers to safely cross between one end of the road and the other [4].

\subsection{MRT-3 Stations}

MRT3 stations are located in North Avenue, Quezon Avenue, Kamuning, Cubao and Santolan-Annapolis, all in Quezon City; Ortigas Avenue in Pasig City; Shaw Blvd. and Boni Avenue in Mandaluyong City; Guadalupe, Sen. Gil Puyat Avenue (Buendia), Ayala Avenue and Magallanes Avenue in Makati City; and Taft Avenue in Pasay City [3,4]. 


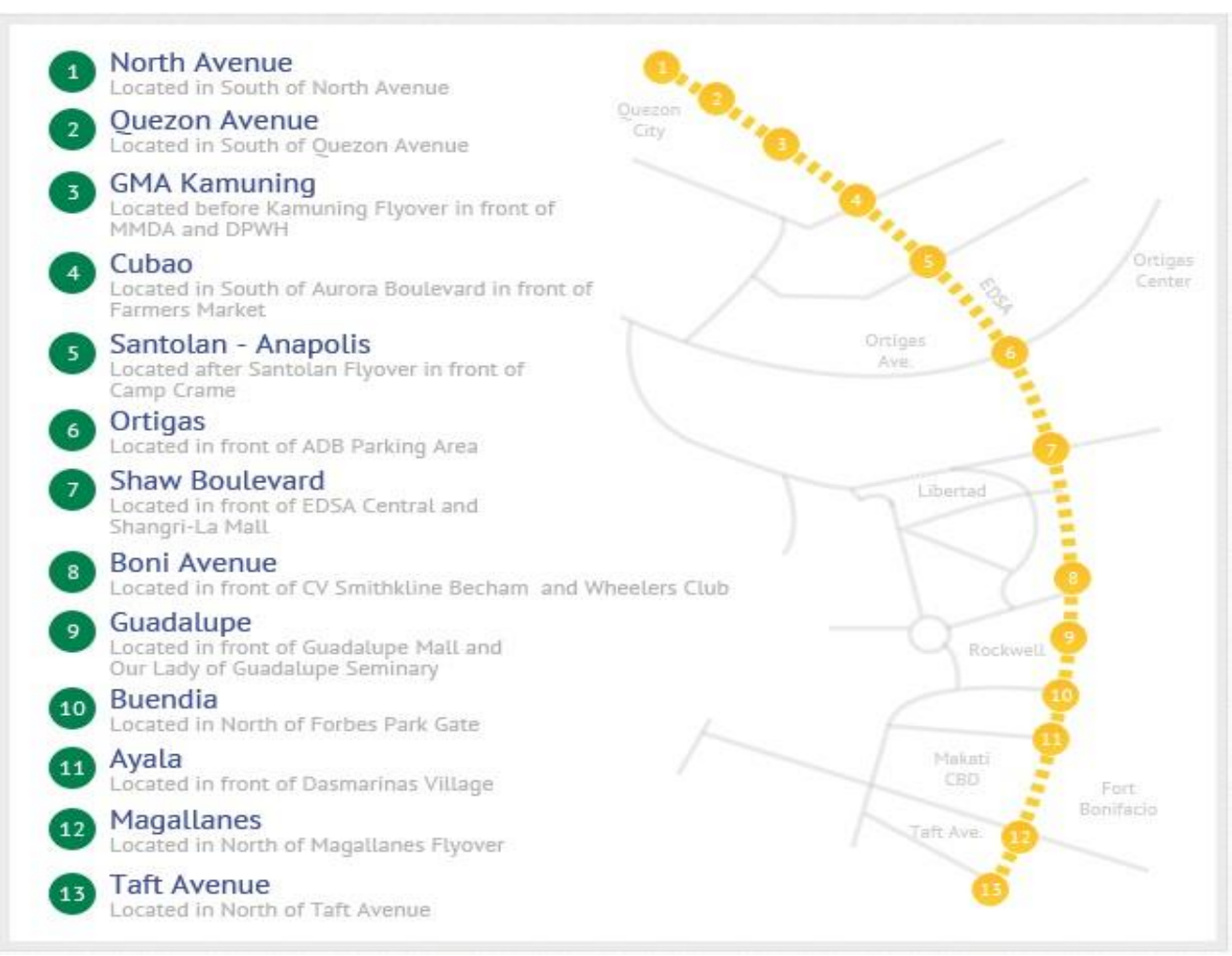

Figure 3. MRT 3 Stations

Three main types of stations were adopted namely: at-grade, eelevated and dexpressed. Stations are averagely spaced 1,300 meters apart; with the closest spacing about 730 meters and the farthest, 2,210 meters, all providing basic disabled friendly and commuter responsive facilities such as platforms, view-decks, elevators and escalators, public crossings and other amenities $[3,4,11]$.

Each station's concourse area is divided into paid and unpaid sections. The paid section is a secured area accessible only to MRT passengers who have bought and inserted a fare ticket in any of the entry gates. The unpaid section is the public section where ticket vending and other commercial vending machines, rail travel and other local transportation information boards, and advertising panels and pedestals are located.

Safety has been stressed in all stations, which are equipped with a modern communications system, closed circuit television for security monitoring, public address system, fire stand pipes and hoses and wash down bibs

\subsection{MRT-3 Depot}

The underground Depot maintenance complex has a total area of 84,444 square meters located at the 16 hectare North Avenue Extension in Quezon City shown in Figure 4. It serves as the headquarters for light and heavy maintenance and operation of the system. 


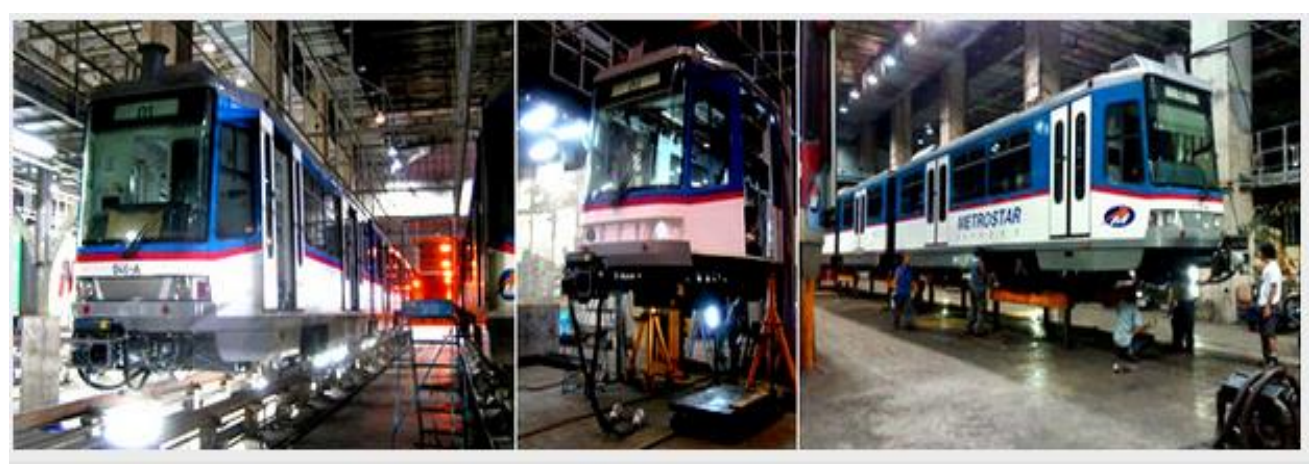

Figure 4. MRT 3 Depot

A spur line connects the depot with the mainline rail tracks, providing ingress and egress for the movement of rail cars from both points. The stabling, which is the temporary storage for revenue vehicle is composed of 9 tracks which is capable of storing 81 rail cars with space provided for the storage of 40 additional rail cars in the future $[1,4,12]$.

\subsection{MRT 3 Ridership}

The MRT-3 System was designed to carry a maximum load of 300,000 riders a day shown in Figure 5. This limit has been breached due to high demand since 2005. Annual ridership increases at an average of 17\%. Ridership from the MRT-3's first full year of operations in 2000, pegged at 39,401,465 riders, more than doubled in 2001 at 90,262, 148 riders $[2,4,13]$. Annual dips in ridership during the month of April is due to the scheduled maintenance of the MRT-3 System, which runs from Maundy Thursday to Easter Sunday.

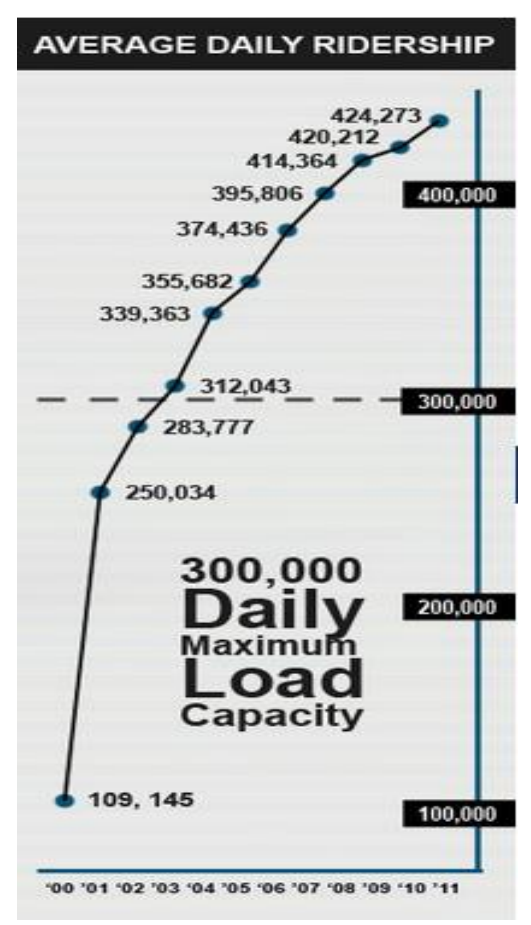

Figure 5. MRT 3 Ridership

\subsection{MRT-3 Signaling and Train Controls}


ATP (Automatic Train Protection) System is a computer based interlocking and signaling and Track Circuit with the Central Control and Monitoring located at the Control Center in North Avenue Station [2,4,14]. The Mainline is divided into 3 local areas, each has a MAN900 computer, an Ebilock 950 Interlocking computer and a back-up Ebilock 950, and a Field Engineering Unit Computer. All areas are controlled by a central MAN 900 computer [2,3]. The whole line is viewed in NR display computer.

2.7.1. Transaction Power System: Operation and maintenance of traction power and composite substations covering fourteen (14) areas (Depot and 13 stations) $[2,4]$. Traction power substation covering eight (8) station supply DC750V OCS power to mainline for train operation, and connected in parallel for flexibility/continuity OCS power supply in case any TPSS station is lost due to MERALCO power failure.

2.7.2. Overhead Catenary System: The Overhead Catenary System being used is based upon range of aluminum components procured from Adtranz of Germany. Other components were sourced from Siemens in Germany and Arthur Flurry in Switzerland $[1,3]$. These components represent a proven technology and has been used widely on rail transportation in Europe. Conductors, clamps and mast were sourced from Australia and Europe with a number of components being manufactured locally. The system consists of an overhead contact system electrified at $750 \mathrm{~V}$ DC. Power is drawn from MERALCO network at $34 . \mathrm{KV}$ phase $60 \mathrm{~Hz}$ and reduced to $750 \mathrm{~V} D C$ at the traction power substations $[2,3]$.

2.7.3 Central Computer System (CCS): Consists of two computers; one for Sales Management and the other for Security.

2.7.4. Station Computer System (SCS): Collects data from all station terminal units. A total of 13 units is installed for the system.

2.7.5. Encoder/Sorter $(\mathbf{E} / \mathbf{S})$ : These machines are used for initialization of blank tickets, tickets for sorting, Security.

2.7.6. Automatic gates (AG): The AG makes a throughput rate of 30 passengers per minute possible. A total of 197 gates are installed for the whole system.

2.7.7. Analyzer/dispenser (AD): Encodes value on initialized ticket to be sold to passengers. A station attendant, for convenience of handicapped passengers, can perform entry or exit process, too. A total of 83 AD's are distributed on the system.

2.7.8. Ticket Issuing Machine (TIM): Installed at each station to cater to single journey ticket.

2.7.9. Radio Communication System: An LRT trunk radio is used to facilitate communication between Control Center and Train Driver using the Mainline Channel, while the Depot Channel is used by the Engineering Department during train movements at Depot ARea and Emer Channel is used by Station's Operation

2.7.10. Public Address System: The Public Address System is used to convey messages to passengers and station personnel. It has 12 preset digital pre-recorded safety messages and 4 track tape console for pipe-in music, and 16 pieces 150 watts power amplifiers to obtain maximum loudness. 
2.7.11. CCTV Monitoring System: This is used for monitoring passengers for safety and surveillance purposes. Cameras are installed in various locations such as platform area, concourse and elevators. These cameras are viewed and monitored at Station Control Room. While at Depot, cameras are installed at different locations and can be viewed and monitored at the Yard Master Room.

2.7.12. PABX Telephone System: Installed at each station to cater to single journey ticket. The System interconnects internal telephone calls and outside calls with the aid of auto attendant computer. It maximizes 20 trunk lines for 32 digital local lines and 150 analog local lines serving 16.9 kilometer main telephone cable with 14 Main Distribution Frames.

2.7.13. Station Building Amenities: These are escalators, elevators, rest rooms \& water supply, sump pumps, video monitors and supervisors \& ticketing room.

\section{Research Design and Instrumentation}

\subsection{Research Design}

The study used the interviews, inferential and descriptive methods of research with questionnaires as the main data-gathering instrument. The subjects of the study were passengers of jeepneys and buses, commuters of MRT, MRT staff and government agencies such as the Department of Public and Highways that has been involved in railway transport strategies. The target population had to be within the catchment of MRT station. A reconnaissance survey was first conducted in June 20, 2013, the period when questionnaires and interview schedules were also formulated, units of observation and analysis identified and sampling procedures designed.

\subsection{Instrumentation}

Direct field observation and recording by the researcher was done by the use of a filed notebook, base map and a camera. To verify all the information provided, the researcher made field observations. Some of the issues that were observed directly include the MRT lines and also the conditions of the existing coaches and engines.

The researcher conducted personal interview of a selected sample respondents using standard structured questionnaires. This gave the researcher the socioeconomic background of the study area. Questionnaires also captured that were informative about the modes affecting Metro Manila commuter rail system in the Metro Manila, the problems of potential train users in facing the MRT transport system .

\section{Findings}

\subsection{Reasons for Commuting with MRT}

As shown in Figure 6, MRT was found to be preferred because it was found to be cheap and convenient. 


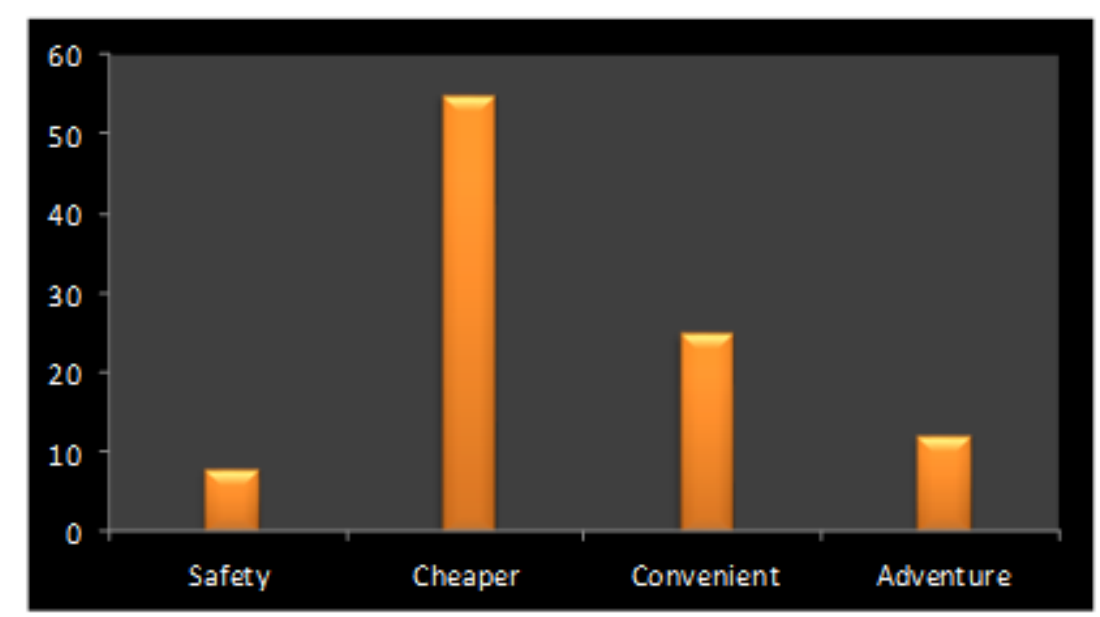

Figure 6. Reasons for Commuting MRT

\subsection{The MRT network within Metro Manila}

The Metro Rail Transit 3 (MRT-3) is the cornerstone of the Department of Transportation \& Communication's integrated strategy to alleviate the chronic traffic congestion experience along the EDSA corridor. The Metro Rail system is designed to carry in excess of 23,000 passengers per hour per direction, initially, and is expandable to accommodate 48,000 passengers per hour, per direction. The train's run every day during the morning, afternoon and evening peak hours and unlike road transport, the train service does not experience traffic jams.

The respondents in this study show that most commuters were $36 \%$ within 2 kilometers and above and $34 \%$ within 500 meters tolkilometer from the MRT railway line. Out of this percentage, only $1 \%$ of the commuters are within 100 meters of MRT railway line as shown in Figure 7.

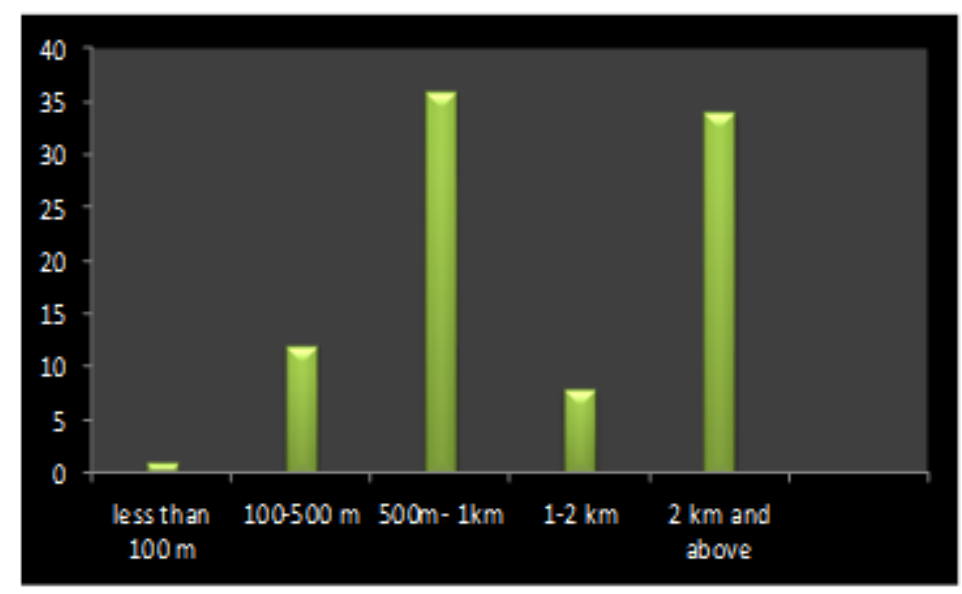

Figure 7. Proximity of MRT to Commuter Residence

\subsection{Utilization of the Commuter Service}

The commuter service is currently being utilized especially between Pasay City and Quezon city. The line service mostly low income earners who find MRT charges friendly to their pockets. They also prefer to use commuter service because the service is faster and very convenient compared to road transport which frequently faces traffic congestion. As shown in Figure 8, 60\% of the respondents prefer to use MRT service because they consider it affordable compared to road 
transport which charges high fares. Figure 8 shows the commuters' rating of the cost of commuter train services against other means of transport. Besides affordability of the MRT services, the commuters also prefer to use the service because it avoids delays as compared to road transport which faces congestion as a result of heavy traffic jam.

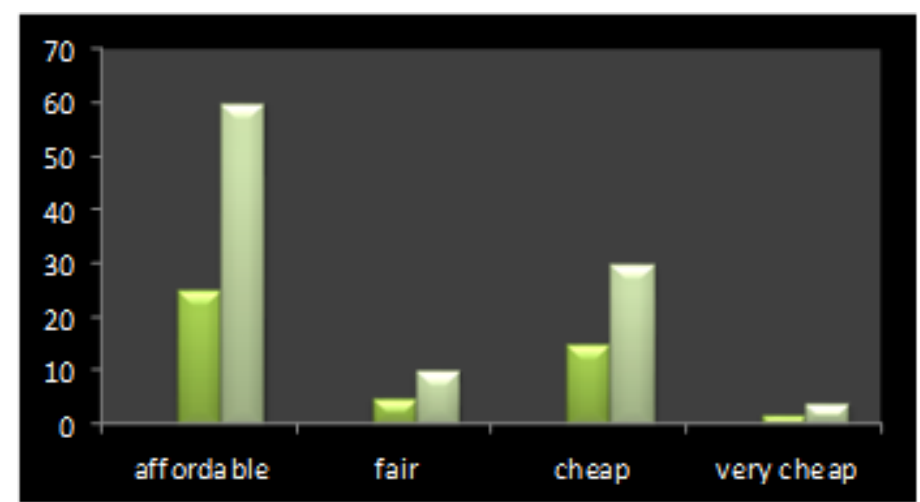

Figure 8. Commuters' Rating of the Cost of the Cost of Commuter MRT Services

\subsection{Commuters Point of View}

As shown in Figure 9, it is evident that despite the good commuter service is currently enjoying Metro Manila residents, there are a number of challenges facing the management.

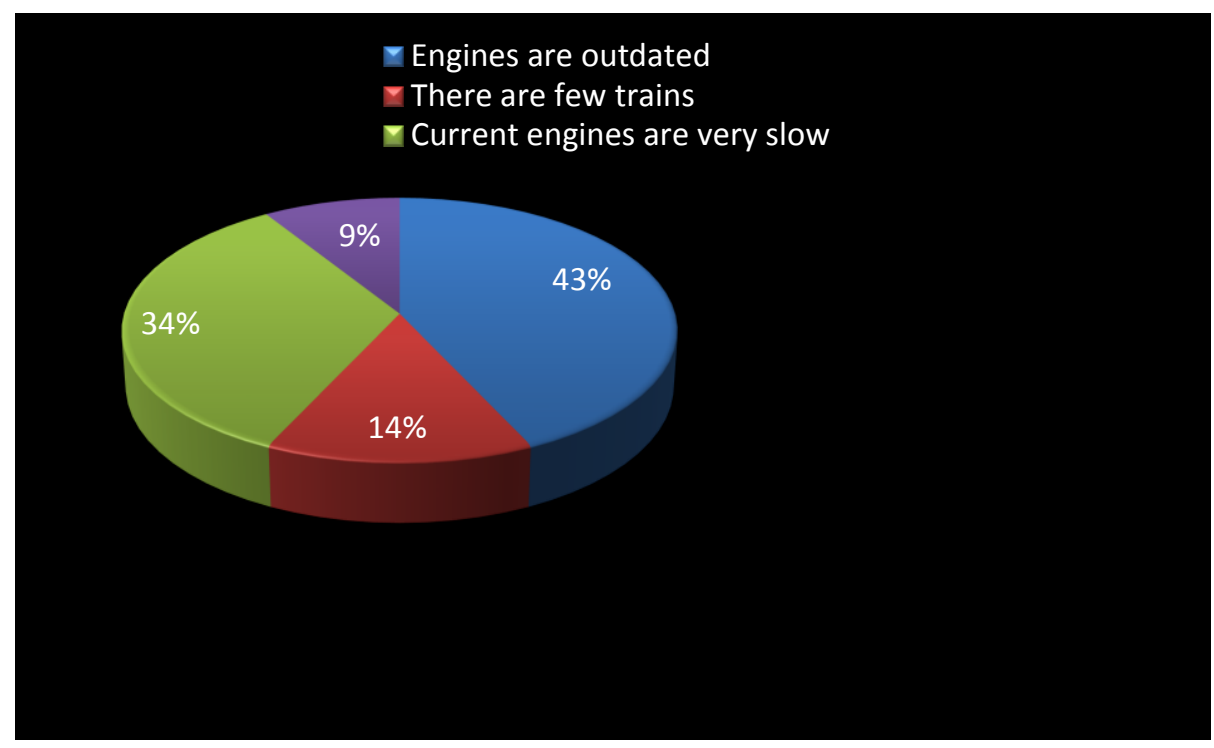

Figure 9. Problems of Commuter MRT Services

The current demand for the service is overwhelming but the supply is constrained due to inadequate MRT network within the Metro Manila region. This problem is compounded by few engines which are not enough to meet the ever-increasing demand. This has in most cases caused serious congestion and some of the passengers who do not find space usually hangout thereby endangering their lives. The engines are also old which make them move at a slower speed compared to Megatren. 


\section{Metro Rail Transit 3 as a Substitute to the Jeepneys and Buses Transport}

Much attention is given to the MRT as a substitute to the jeepneys and buses and as a possible solution to the congestion and environmental problems faced by the land transport industry, although substituting jeepneys and buses are not the main reason for introducing MRT. Due to its speed and the location of most MRT stations at the city centre, the MRT can offer comparable or shorter travel times than the jeepneys and buses on some routes and can therefore substitute it.

The travel time advantage depends on the average speed of the MRT service and the distance each mode has to cover. The MRT ceases to be a good substitute for the buses and jeepneys (e.g. between Pasay Road to Quezon Boulevard, the MRT share of the traffic is only 10\%). In between these distances, there is usually direct competition between the modes. In most cases, competition is also between the operators of buses and jeepneys. This competition means that MRT services are added to the buses and jeepney services and not really substituting them.

Nevertheless, the MRT has an important role to play in the future of the buses transport industry and in relieving the congestion and environmental problems it faces. In summary, it is through integration between the two modes, and not competition, that the buses transport industry will see an opportunity in MRT services and will strive to substitute the jeepneys and buses by MRT (on routes where the latter offers travel time savings).

\section{Environmental Impact of the MRT-3}

The impact of MRT operations on the environment is usually portrayed in a positive light since it is considered to impact the environment less than other modes of transport. Locally, along the MRT lines, noise nuisance from MRT operations can be considered as the main environmental impact of the MRT. The level of noise generated depends mainly on the speed of the train. At speeds between 50 and 300 $\mathrm{kph}$, rolling noise is the most important noise source and it depends mainly on the smoothness of the wheels and railhead. The high standards of the MRT infrastructure (the trains used and the construction and maintenance standards) probably leads to less noise generated from MRT operations in comparison with conventional trains running at the same speed. Only at speeds above $300 \mathrm{kph}$ does aerodynamics become the main source of noise. Thus, even for MRTs, rolling noise is probably the dominant source of noise. At high speeds MRT operations result in high levels of noise, yet the impact of this (the actual noise heard and number of people exposed to it) is lower than can be expected since in densely populated areas the speed of the MRT is usually at its lowest (due to the distance required for the MRT to stop, which means speed is reduced far from the station). In addition, it is possible to protect people from railway noise by building barriers.

With regard to noise pollution, it is less clear whether the aircraft or the MRT leads to more noise pollution, and analysis on a route basis is required, yet it is easier to provide protection from MRT noise than from other transport noise. MRT infrastructure and operations certainly result in adverse impacts on the environment, mainly by affecting LAP, causing a noise nuisance and consuming land. There is also evidence that MRT operations impact the environment less than the buses and the car when these modes are compared on the same basis. However, whether the introduction of new MRT infrastructure and services leads to environmental benefits is less clear. In addition, the 


\section{Conclusion}

It's possible that MRT can deliver socio-economic benefits and mainly improve the accessibility of the cities it serves. Yet, this presents a dilemma to policy-makers and planners. To increase the overall benefits of the MRT and decrease its negative effects, it should serve many cities and include many stops, but more stations on an MRT line lead to a lower average speed and thus to lower capacity on the route and a longer travel time, reducing the benefits of the MRT. To ensure that Metro Manila commuter train system could function adequately in terms of both the provision of services and operating costs, it is essential to get rid of the mindset that associates public transport systems with the poor and to enhance the systems so that these can be used safely by people of all classes.

\section{References}

[1] About Us, MRT 3 stations. Metro rail transit, (2014) July 14 . Retrieved from http://dotcmrt3.gov.ph/about.php?route=7.

[2] About Us, MRT 3 stations. Background, (2014) July 14. Retrieved from http://dotcmrt3.gov.ph/about.php?route=4.

[3] About Us, MRT 3 stations. MRT 3 trains, (2014) July 14. Retrieved from http://dotcmrt3.gov.ph/about.php?route=6.

[4] R. A. Ronda, "LRT, MRT closed for holy week", The Philippine Star, (2010) March 31.

[5] R. T. Olchondra, "MRT-3 rides to go 24 hours starting June 1", Philippine Daily Inquirer, (2009) May 29.

[6] A. Kwok, "MRT-3 stops 24-hou run”, Philippine Daily Inquirer, (2009) July 3.

[7] M. R. Camus and P. Nina, "DOTC extends MRT-3 operating hours", Philippine Daily Inquirer, (2014) March 11.

[8] J. H. Macaspac and M. L. Garcia, "First phase of Edsa metro rail transit system underway", Manila Standard, Kamahalan Publishing Corporation, (1996) March 28.

[9] T. U. Ganiron Jr, "Investigation on the use of sosrobahu technology as road construction technique", International Journal of Advanced Science and Technology, vol. 65, (2014) April, pp. 27-38.

[10] T. U. Ganiron Jr, "Analysis of double meridian distance for a closed traverse area towards developing a contour map and land title", Journal of Engineering Science and Technology Review, vol. 7, no. 2, (2014) July, pp. 39-46.

[11] T. U. Ganiron Jr, J. Eje and J. Gemparo, "The traffic congestion problem”, BS Thesis, Civil Engineering Department, FEATI University, Manila, (2002).

[12] T. U. Ganiron Jr, A. Latoja, J. Andan, F. Amolong and L. Joseph, "EDSA MRT", BS Thesis, Civil Engineering Department, FEATI University, Manila, (1998).

[13] T. U. Ganiron Jr, J. Aparato, M. Abayon, M. Baybay and R. Sison, "A study on the development of skyway systems (Phase 2: Nichols toll plaza to Bicutan) Its trends and impact to the commuters", Civil Engineering Department, FEATI University, Manila, (2000).

[14] T. U. Ganiron Jr, "A practicum report in Metro Manila Skyway projects (Stage 1-Buendia to Bicutan)", Master's Project, Civil Engineering Department, De La Salle University, Manila, (1997).

\section{Author}

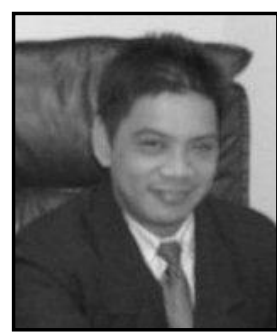

Tomas U. Ganiron Jr., he obtained his Doctor of Philosophy in Construction Management at Adamson University (Philippines) in 2006, and subsequently earned his Master of Civil Engineering major in Highway and Transportation Engineering at Dela Salle University-Manila (Philippines) in 1997 and received Bachelor of Science in Civil Engineering major in Structural Engineering at University of the East (Philippines) in 1990. He is a registered Civil Engineer in the Philippines and Professional Engineer in New Zealand. His main areas of research interest are construction engineering, construction management, project management and recycled waste materials.

Dr. Ganiron $\mathrm{Jr}$ is a proud member of professional organizations like the Institution of Engineers-Australia and 
American Society of Civil Engineer. He is also very active in other professional groups like Railway Technical Society of Australasia and Australian Institute of Geoscientists where he became committee of Scientific Research. He has given invited or keynote lectures at a number of international conferences and has received the ASTM Award CA Hogentogler for 2008 in New Zealand and Outstanding Researcher for 2013 in Qassim University. 